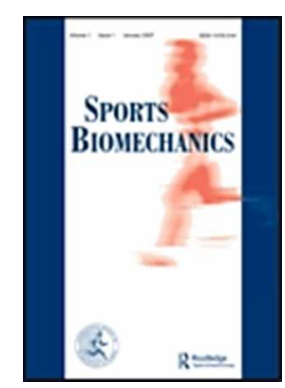

\title{
Upper limb muscle fatigue during prolonged Boccia games with under arm throwing technique
}

\begin{tabular}{|r|l|}
\hline Journal: & Sports Biomechanics \\
\hline Manuscript ID: & RSPB-2011-0184.R2 \\
\hline Danuscript Type: & Original Research \\
\hline Complete List of Authors: & $\begin{array}{l}\text { Yam, Kit Yee; The Chinese University of Hong Kong, Orthopaedics and } \\
\text { Traumatology } \\
\text { Fong, Daniel; The Chinese University of Hong Kong, Orthopaedics and } \\
\text { Traumatology } \\
\text { Chu, Vikki; The Chinese University of Hong Kong, Orthopaedics and } \\
\text { Traumatology, } \\
\text { Cheung, Roy; Harvard Medical School, Physical Medicine and Rehabilitation } \\
\text { Chan, Kai-Ming; The Chinese University of Hong Kong, Orthopaedics and } \\
\text { Traumatology }\end{array}$ \\
\hline Keywords: & $\begin{array}{l}\text { Paralympics, Throwing < Fundamental Skills, Muscle Mechanics < Methods, } \\
\text { Performance < Sport Topics, Electromyography }\end{array}$ \\
\hline &
\end{tabular}

\section{SCHOLARONE"}

Manuscripts 


\begin{tabular}{|c|c|}
\hline Title & $\begin{array}{l}\text { Upper limb muscle fatigue during prolonged Boccia games with } \\
\text { under arm throwing technique }\end{array}$ \\
\hline Authors & $\begin{array}{l}\text { Kit Yee YAM }{ }^{1,2} \text {, Daniel Tik-Pui FONG }{ }^{1,2} \text {, Vikki Wing-Shan } \\
\mathrm{CHU}^{1,2} \text {, Roy Tsz-Hei CHEUNG }{ }^{3} \text {, Kai-Ming } \mathrm{CHAN}^{1,2}\end{array}$ \\
\hline Affiliation & $\begin{array}{l}{ }^{1} \text { Department of Orthopaedics and Traumatology, Prince of Wales } \\
\text { Hospital, Faculty of Medicine, The Chinese University of Hong } \\
\text { Kong, Hong Kong, China. } \\
{ }^{2} \text { The Hong Kong Jockey Club Sports Medicine and Health } \\
\text { Sciences Centre, Faculty of Medicine, The Chinese University of } \\
\text { Hong Kong, Hong Kong, China. } \\
{ }^{3} \text { Department of Physical Medicine \& Rehabilitation, Harvard } \\
\text { Medical School, Harvard University, Boston, USA. }\end{array}$ \\
\hline $\begin{array}{l}\text { Corresponding } \\
\text { author }\end{array}$ & $\begin{array}{l}\text { Prof Daniel Tik-Pui FONG, } \\
\text { Department of Orthopaedics and Traumatology, Prince of Wales } \\
\text { Hospital, Faculty of Medicine, The Chinese University of Hong } \\
\text { Kong, Hong Kong, China } \\
\text { Email: } \underline{\text { dfong@ ort.cuhk.edu.hk }} \\
\text { Tel : (852) } 26323535\end{array}$ \\
\hline Keywords & $\begin{array}{l}\text { Paralympics, throwing, muscle mechanics, performance, } \\
\text { electromyography }\end{array}$ \\
\hline Acknowledgement & $\begin{array}{l}\text { This research project was made possible by resources donated by } \\
\text { The Hong Kong Jockey Club Charities Trust. This paper was proof } \\
\text { read by Mr. Kiron Ken Athwal. }\end{array}$ \\
\hline
\end{tabular}




\begin{abstract}
This study investigated 1) the acute fatigue pattern in neuromuscular activity after a simulated Boccia game; and 2) the effect of fatigue pattern on sport performance. Nine elite Boccia athletes were tested before, during and after a simulated game. Maximal ball speed was captured with video; and the target hitting rate and rating of perceived exertion (RPE) score were collected and analyzed. Electromyography (EMG) signals from the upper trapezius, anterior deltoid, posterior deltoid, biceps brachii, triceps brachii and wrist extensor muscles were collected by surface electrode, and were evaluated with mean power frequency (MPF). Only the upper trapezius muscle showed fatigue as demonstrated by a reduction in MPF of $8 \%(\mathrm{p}=0.027)$ when comparing the first and last throws in a simulated game. Subjective RPE score increased during the game $(118 \%, \mathrm{p}=0.004)$, and sports performance in terms of maximum ball speed and target hitting rate also deteriorated $(12 \%, \mathrm{p}=0.004$ and $25 \%, \mathrm{p}=0.004$, respectively). In conclusion, fatigue on the upper trapezius muscle was demonstrated in elite Boccia athletes following a prolonged Boccia game and may have affected Boccia performance. Preventative measures against upper trapezius muscle fatigue and endurance training for synergists of the upper trapezius muscle may be considered in future studies.
\end{abstract}




\section{Introduction}

Boccia was originally designed for individuals with cerebral palsy (CP), but is now played by athletes with other severe disabilities affecting motor skills such as spinal muscular atrophy (SMA). There are competitions at both national and international level for disabled athletes who require wheelchairs for locomotion. In 1984 Boccia became a Paralympic sport, and by 2008 it was being practiced in over fifty countries worldwide. The sport is administered by the International Boccia Committee (IBC), which is governed by the Cerebral Palsy International Sports and Recreation Association (CPISRA). All events are mixed in gender and feature individual, pair and team competitions.

Depending on their physical and functional abilities, Boccia athletes are assigned to one of four sports classes, BC1 to BC4 (Cerebral Palsy International Sports \& Recreational Association, 2009). They aim to score by throwing colored balls as close as they can to a white target ball, the "jack". The colored balls are allowed to be thrown by hand, kicked by feet, or, if the competitor's disability is severe, launched with an assistive device. At the end of each round, or end, the referee measures the distance of the colored balls closest to the jack, and awards points accordingly. The team/player with the highest number of points at the end of game is the winner. Therefore, this sport requires a high degree of muscle control, accuracy, concentration and tactical awareness.

This fast growing indoor sport becomes more competitive with increasing physical demand. With the high demand of motor performance in the upper extremity, muscle fatigue is one of the major complaints from Boccia athletes during a game. There is no 
previous study about muscle fatigue for this Paralympic sports. Understanding Boccia specific upper limb muscle recruitment, the presence and pattern of muscle fatigue in elite athletes may help physiotherapists, trainers and coaches to refine training and rehabilitation protocols for sport performance enhancement.

Muscle fatigue is used to denote a transient decrease in the capacity to perform physical actions (Enoka \& Duchateau, 2008). It is a chain of metabolic, structural and energetic changes in muscles due to insufficient oxygen and nutritive substances supplied through blood circulation, as well as a result of changes in the efficiency of the nervous system (Cifrek et. al., 2009). Biochemical and physiological changes in muscle during fatiguing contractions are also reflected in the properties of myoelectric signals recorded on the surface of the skin above the muscle(s) concerned (De Luca, 1984). Surface electromyography (EMG) is one method used to monitor local muscle fatigue during performance. One consequence of the muscle contraction is the increase in the concentration of lactic acid. At a certain level of contraction, blood flow is stopped by intramuscular pressure and the muscle becomes ischemic. Increased concentration of the lactates is responsible for fatigue by changes in intracellular $\mathrm{pH}$. The decrease of $\mathrm{pH}$ determines the decrease of muscle fibre conduction velocity, and as a consequence the decrease of mean power frequency (MPF) (Brody et. al. 1991). Therefore the lowering of muscle fibre conduction velocity is one of the causes of signal power spectrum shift toward lower frequencies, and also of the increase in surface EMG signal amplitude because of a spatial low-pass filtering effect of tissue as a volume conductor (Cifrek et. al., 2009). De Luca (1997) recommended using the MPF calculated from the frequency spectrum of the EMG signal as the fatigue index because it is less sensitive to noise and signal aliasing, and in most cases more sensitive to the biochemical and physiological processes that occur within the muscles during sustained contractions (De Luca, 1997). 
Muscle fatigue is also defined as an exercise-induced reduction in the ability of muscle to produce force or power to ensure whether or not the task can be sustained (Bigland-Ritcie \& Woods, 1984; Søgaard et.al., 2006). Thus the fatigue pattern is likely to be rather specific from one sport to another. Most of the Boccia athletes throw using an 'under arm' method and not an overhead action (Figure 1). There is lack of knowledge about the effect of muscle fatigue for this throwing performance in this specific subject group.

Hence, This study aimed to investigate 1) the acute fatigue pattern in neuromuscular activity of elite Boccia athletes after a simulated game; and 2) the effect of fatigue pattern on their sport performance. The null hypothesis was that the mean power frequency (MPF) of the EMG signal of selected muscle groups during an under arm throw would not differ during a simulated Boccia game. This study would contribute to the refinement of an upper limb muscle endurance training program for performance enhancement.

\section{Method}

\subsection{Subjects}

All qualified Boccia athletes who used an 'under arm' throwing technique either with CP or SMA were recruited from the national Boccia team of Hong Kong Paralympic Committee \& Sports Association for the Physically Disabled. Athletes in the BC3 class who used assistive device; athletes who used overhead throwing, bilateral hands throwing, or foot kicking techniques; as well as those who had upper limb fracture or received upper limb surgery in the preceeding 12 months were excluded. Sample size 
estimation was based on a previous study, which reported that the increase of MPF in vastus lateralis was $7 \mathrm{~Hz}$, with a common standard deviation of $3.75 \mathrm{~Hz}$ (Thorlund et. al., 2008) in a group of fatigued athletes. By setting the level of significance to 0.05 and the statistical power to 0.80 , the estimated required sample size was 2.25 . A total of nine subjects, including three $\mathrm{BC} 1$, four $\mathrm{BC} 2$ and two $\mathrm{BC} 4$, were enrolled in the current study. There were six subjects with CP and three subjects with SMA, whose ages ranged from 15 to 43. Their Boccia experience ranged from two to 11 years. The university ethics committee approved the study. Written consent was obtained from all the subjects at least one week prior to the test.

\subsection{Procedures}

The test was conducted on the training field. The subject was seated on his/her own wheelchair used for competitions. Based on the 'under arm' throwing action, the major group of upper limb muscles of the dominant hand, i.e. upper trapezius, anterior deltoid, posterior deltoid, biceps brachii, triceps brachii and wrist extensor, were chosen for this study. The skin surface of the selected muscles was shaved to remove hair, lightly abraded and cleaned with alcoholic wipe to facilitate good electrode attachment. The electrode used was 3M Red Dot Electrode 2238 and the diameter was $6 \mathrm{~cm}$. This EMG device was telemetric. All the electrodes (Noraxon TeleMyo 2400T G2, USA) were placed in the middle of muscle bulks and aligned in parallel with the muscle fibers based on the recommendations of the SENIAM Project (Hermens et. al., 1999). A reference electrode was positioned on the lateral epicondyle of the elbow. Ten balls were 
then thrown behind the frontline as warm up. Each ball weighed $275 \pm 12$ grams. A five minute rest was given before executing the isometric electromyography test.

\subsubsection{Isometric electromyography test}

The subject was asked to hold a colored ball and flex the shoulder at 45 degrees for five seconds, then extend at 30 degrees for five seconds (Figure 2). Myoelectric signals were recorded at the two static positions as the isometric test. Oberg et al. (1990) suggested that the MPF value obtained initially can be used within the functional range of movement to calculate the relative decrease in MPF as a result of muscle fatigue. The flexion and extension positions chosen were the common active throwing range of motions in Boccia athletes. EMG data from these two isometric tests were compared before and after the simulated game to detect the presence of muscle fatigue.

\subsubsection{Maximum ball speed test}

The subject was instructed to throw three balls a minimum horizontal distance of a meter in the air, with as much ball speed as possible to prevent frictional force from the floor. Videotaping with a high speed video camera (Casio EX-F1, Japan) at $300 \mathrm{~Hz}$ filming rate was set to collect data, and then a motion analysis system (Kwon3D, USA) was used to determine the maximal ball speed. Average speed was calculated in the first meter beyond the front line. Ball speed was compared before and after the simulated game to detect the change of performance. A five minute rest was given after the test.

\subsubsection{Rating of perceived exertion}

The validated subjective score of rating of perceived exertion (RPE) from six to 20 was measured before and after the simulated game (Leung et. al., 2004; Borg, 1985). The 
American College of Sports Medicine (2000) has recommended RPE as a valid and reliable indicator of exercise intensity. The pre- and post-game RPE score was compared to detect the presence of subjective fatigue feeling.

\subsubsection{Simulated game electromyography test and target hitting rate}

In a real game, individual competitions consist of four ends and six balls per player per end. Three games are commonly played in one day during the international games. In this study, the simulated game situation was designed for better standardization and to reduce the variation caused by different competitors. The jack was placed six meters away from the frontline. The subject was asked to throw a total of 72 balls to hit the target. Myoelectric signals of upper limb muscles were collected and synchronized video was recorded during the game at the first, 12th, 24th, 36th, 48th, 60th and 72th throws. EMG data collected from the throws were used to calculate MPF. The number of balls that hit the jack was also counted to calculate the target hitting rate in every 24 throws. The first 24-ball and last 24-ball target hitting rates in percentage were compared for detecting the change of performance. Immediately after the simulated game, the RPE, maximum ball speed and isometric tests were repeated.

\subsection{Electromyography signal processing}

The myoelectric signals of the whole forward swing phase from each muscle channel during the simulated game were trimmed. The EMG signals of both isometric test and simulated game test were full-wave rectified, and then the data were filtered using a Butterworth filter with band-pass of 20 to $500 \mathrm{~Hz}$. A fast Fourier transform was used to compute the MPF of the power spectrum for analysis of muscle fatigue. Normalization was performed by dividing all calculated MPF data by the initial values of the individual trials in each test series, i.e. isometric flexion test, isometric extension test and simulated 
game EMG test. Therefore, those data were presented as percentages as shown in the charts of results to facilitate comparisons between muscle groups.

\subsection{Statistical analysis}

Descriptive statistics were expressed as means \pm SD. A nonparametric test was chosen because of the small number of studied subjects. Differences between isometric test EMG data, maximum ball speed and RPE before and after the simulated game, as well as first and last 24 balls target hitting rate were determined using a Wilcoxon signed rank test. Friedman 2-way ANOVA was used to detect the differences of MPF during 72 throws at different time points. The level of significance was established at $\mathrm{P}<0.05$.

\section{Results}

\subsection{Isometric electromyography test}

The descriptive statistics and results of Wilcoxon Signed Ranks test are shown in Table 1. There was no significant difference of MPF in any tested muscle in either isometric flexion or isometric extension before and after the simulated game. In flexion, although not statically significant, there were trends of reducing MPF in wrist extensor $(-4.3 \%$,

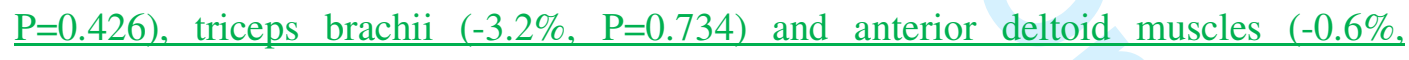
$\underline{\mathrm{P}=0.734)} . \underline{\text { In extension, although not statically significant again, similar trends were }}$ observed in biceps brachii $(-0.6 \%, \mathrm{P}=0.570)$, anterior deltoid $(-1.3 \%, \mathrm{P}=1.000)$ and upper trapezius muscles $(-1.8 \%, \mathrm{P}=0.426)$.

4.2. Simulated game electromyography test 
The descriptive statistics and results of Wilcoxon Signed Ranks test are summarized in Table 2. Upper trapezius muscle showed significant decrease in MPF when comparing the first and last throw in the simulated game $(\mathrm{P}=0.027)$. There were decreasing MPF trends in the wrist extensor $(-0.1 \%, \mathrm{P}=0.426)$, anterior deltoid $(-1.7 \%, \mathrm{P}=0.652)$ and poster deltoid muscles $(-2.3 \%, \mathrm{P}=0.570)$ but were deemed statistically not significant.

When comparing the MPF during the simulated game at different time points (at first, 12th, 24th, 36th, 48th, 60th and 72th throws), no statistically significant difference was shown in any tested upper limb muscle (Figure 3).

\subsection{Simulated game target hitting rate}

There was a significant decrease of target hitting rate when comparing the first 24 throws and the last 24 throw as shown in Table $3(\mathrm{P}=0.004)$.

\subsection{Rating of perceived exertion and maximum ball speed}

There was a significant increase of RPE score, which suggests an increase of physical stress, effort, and fatigue after the simulated game ( $\mathrm{P}=0.004)$ (Borg, 1985) (Table 3). The maximum ball speed also showed a significant drop after the simulated game $(\mathrm{P}=0.004)$ (Table 3).

\section{Discussion}

The present study examined the acute fatigue-induced impairment of muscle neuromuscular activity in elite Boccia athletes following simulated games. There was no reduction of MPF shown in any of the tested upper limb muscles during the isometric test and in repeated measures during the simulated game. Only the upper trapezius muscle showed a reduction in MPF when comparing the first and 72th throws. The 
subjective RPE score increased with the drop in sports performance determined by the maximum ball speed and target hitting rate.

In this study, the upper trapezius was the only muscle that had a significant decrease in MPF following simulated Boccia game. The upper trapezius muscle met the $8 \%$ decline threshold for fatigue which is a recommended cut-off to signify local muscle fatigue (Oberg et. al., 1990). Upper trapezius muscle likely contributes to scapula upward rotation indirectly by elevating the distal clavicle, which allows the scapula to rotate. Scapula upward rotation provides a stable base of support for the humeral head, increases upper extremity elevation range of motion, maintains deltoid muscle length tension in a functional range, and moves the acromion away from the humeral tuberosities. In addition to upward rotation, the scapula tilts posteriorly and externally rotates to move the acromion away from the path of the elevating humerus and maintain the subacromial space (Szues et. al., 2009). Therefore this is a very important stabilizing muscle for shoulder movement. Our result may reflect that the upper trapezius muscle plays an important role in the 'under arm' throwing action in different classes of elite Boccia athletes. Furthermore, upper trapezius muscle fatigue may contribute to the reduction of Boccia specific performance.

There were previous studies showing that a reduction in muscle EMG potentially leads to a negative impact on functional performance in different sports (Thorlund et. al., 2008; Thorlund et. al., 2009; Zory et. al., 2006). Thorlund et al. concluded that maximal and rapid muscle force characteristics were acutely affected concurrently with marked reductions in muscle EMG following a handball match play, which may potentially lead to impaired functional performance in terms of maximal jump height (Thorlund et. al., 2008). Zory et al. stated that the MPF of lower limb muscles decreased significantly 
after the cross-country skiing $\mathrm{KO}$ sprint associated with changes in the final sprint velocity, lactate concentration, knee-extensor strength, and upper-limb power (Zory et. al., 2006). The results in the present study were comparable to those of other studies that showed that fatigue would affect sports performance.

There was no statistically significant difference for any tested upper limb muscle in repeated measurement, even for the upper trapezius muscle. Sample size calculation is based on the formula for estimating the sample size for a paired t-test but there is no algorithm for rank tests (Norman \& Streiner, 1994). Sample size may be too small to perform the repeated measurement.

The method for measuring muscle fatigue may be another potential reason for non-significant results of MPF in the other upper limb muscles. In the current experiment, the selection of isometric test positions was based on the common range of motions during the 'under arm' throw in subjects with CP and SMA with reference from previous study (Larsson et. al., 1995). These positions may not be specific enough to each upper limb muscle groups. Therefore isometric test may not be suitable for detection of muscle fatigue in this study. For the simulated game test, EMG data collected during the 72 throws may be not rhythmical (Merletti et. al., 2004). De Luca (1997) commented that the MPF should be calculated only when the EMG signal is reasonably stationary and detected at the same phase during a repetitive dynamic contraction. In this study, muscle activities may not be consistent with each throw, which makes the change of EMG data not easily detectable.

RPE score is the subjective score that needed to be interpreted carefully. The significant increase of RPE score in the study may be due not only to muscle fatigue, but also 
factors outside the neuromuscular system. Subjective fatigue feeling may be caused by factors outside the neuromuscular system. Fatigue can be a peripheral phenomenon and also a central phenomenon (Dalsgaard \& Secher, 2007). Thus, RPE score might reflect such a fatigue of a combination of muscle fatigue (upper trapezius \pm some other muscles), and/or other physiological changes that were not measured.

Success in sports, as measured by competitive performance, is dependent upon a number of significant mental and physical components. Somatotype, motor skills, age, nutritional status, physiology, psychology, training level, genetic endownment, and injury risk are the major independent variables influencing performance (Birrer \& Levine, 1987). In this study, only muscle fatigue was investigated, therefore reduction of performance could be associated with other factors.

There were only nine subjects recruited in the study, which included athletes with two different pathologies, as well as athletes with variable years of experience. Athletes with CP or SMA may use different upper limb muscles during the throw. Fatigue pattern may also be different in athletes with different experiences. Fatigue is likely to be less in well trained individuals, not only because of adaptations in muscle machinery which favor high performance and endurance, but because this training process improves the conscious or unconscious 'skill' in optimizing the function of the muscles in such a way as to minimize the tendency to develop fatigue (Gibson \& Edwards, 1985). So the results may be less powerful with a small sample size and various subject groups. However, all the available qualified Boccia athletes were recruited in this study. Therefore, this study has included the whole population in Hong Kong.

\section{Conclusion}


Muscle fatigue of the upper trapezius, in terms of MPF drop, was demonstrated in athletes with CP and SMA following prolonged Boccia game. The observed decline in MPF of upper trapezius muscle may have affected Boccia performance in terms of ball speed and target hitting rate, and was accompanied by increase of subjective exertion. Based on the findings, preventative measures against upper trapezius muscle fatigue and endurance training for synergists of upper trapezius muscle can be considered in future studies. Muscle fatigue may potentially lead to impaired functional performance in the latter part of the game. The reduction in ball speed will likely have a negative impact on the ability to use tactics.

Future studies should be conducted including scapular and trunk muscles in fatigue analysis, and specific intervention studies should be conducted to investigate the impact of different exercises or skill improvement regimes on performance enhancement in Boccia athletes. 


\section{References:}

American College of Sports Medicine. (2000). Guidelines for exercise testing and prescription $\left(6^{\text {th }}\right.$ ed.). Philadelphia, PA: Lippincott Williams, \& Wilkins.

Bigland-Ritchie, B., Woods, J. J. (1984). Changes in muscle contractile properties and neural control during human muscular fatigue. Muscle Nerve, 7, 691-699.

Birrer, R. B., Levine, R. (1987). Performance parameters in children and adolescent athletes. Sports Medicine, 4(3), 211-227.

Borg, G. (1985). An introduction to Borg's RPE-scale. Ithaka, NY: Mouvement Publications

Brody, L. R., Pollock, M. T., Roy, S. H., De Luca, C. J., Celli, B. (1991). pH-induced effects on median frequency and conduction velocity of the myoelectric signal. $\underline{\text { Journal }}$ of Applied Physiology, 71 (5), 1878-1885.

Cerebral Palsy International Sports \& Recreation Association (2009). CPISRA Sports Manual $10^{\text {th }}$ Edition: Section B - Sports Rules - Boccia. Retrieved from http://www.cpisra.org/files/manual10p/CPISRA_Sports_Manual_10th_Edition_Section _B_Sports_Rules_Boccia_2010-02_Release_006.pdf

Cifrek, M., Medved, V., Tonkovic, S., Ostojic, S. (2009) Surface EMG based muscle fatigue evaluation in biomechanics. Clinical Biomechanics, 24, 327-340.

Dalsgaard, M. K., Secher, N. H. (2007). The Brain at work: a cerebral metabolic manifestation of central fatigue? Journal of Neuroscience Research, 85, 3334-3339. 
De Luca, C. J. (1984) Myoelectrical manifestations of localized muscular fatigue in humans. Critical Review of Biomedical Engineering, 11 (4), 251-279.

De Luca, C. J. (1997). The Use of Surface Electromyography in Biomechanics. Journal of Applied Biomechanics, 13, 135-163.

Enoka, R. M., Duchateau, J. (2008). Muscle fatigue: what, why and how it influences muscle function. Journal of Physiology, 586(1), 11-23.

Gibson, H., Edwards, R. H. T. (1985). Muscular Exercise and Fatigue. Sports Medicine, 2, 120-132.

Hermens, H. J., Freriks, B., Merletti, R., Rau, G., Disselhorst-Klug, C., Stegeman, D. F., Hagg, G. M. (1999). European Recommendations for Surface Electromyography: Results of the SENIAM Project. Roessingh Research and Development, Enschede, Netherlands

Larsson, S. E., Cai, H., Zhang, Q., Larsson, R., Oberg, P. A. (1995). Microcirculation in the upper trapezius muscle during sustained shoulder load in healthy women- and endurance study using percutaneous laser-doppler flowmetry and surface electromyography. European Journal of Applied Physiology, 70, 451-456.

Leung, R. W., Leung, M. L., Chung, P. K. (2004). Validity and reliability of a Cantonese-translated rating of perceived exertion scale among Hong Kong adults. Perceptual \& Motor Skills. 98(2):725-735. 
Merletti, R., Rainoldi, A., Farina, D. (2004). Myoelectric Manifestations of muscle fatigue. In Merletti R, Parker P (Eds.), Electromyography: Physiology, Engineering, and Non-Invasive Applications (pp. 222-223). Hoboken NJ: IEEE: Wiley-Interscience.

Norman, G. R., Streiner, D. L. (1994). Biostatistics: the Bare Essentials, (pp. 264-265). St. Louis: Mosby.

Oberg, T., Sandsjo, L., Kadefors, R. (1990). Electromyogram mean power frequency in non-fatigued trapezius muscle. European Journal of Applied Physiology, 61, 362-369.

Szues, K., Navalgund, A., Borstad, J. D. (2009). Scapular muscle activation and co-activation following a fatigue task. Medical \& Biological Engineering \& Computing, 47, 487-485.

Søgaard, K., Gandevia, S. C., Todd, G., Petersen, N. T., Taylor, J. L. (2006). The effect of sustained low-intensity contractions on supraspinal fatigue in human elbow flexor muscles. Journal of Physiology, 573, 511-523.

Thorlund, J. B., Michalsik, L. B., Madsen, K., Aagaard, P. (2008) Acute fatigue-induced changes in muscle mechanical properties and neuromuscular activity in elite handball players following a handball match. Scandinavian Journal of Medicine \& Science in Sports, 18(4), 462-472.

Thorlund, J. B., Madsen, K., Aagaard, P. (2009) Rapid muscle force capacity changes after soccer match play. International Journal of Sports Medicine, 30(4), 273-278. 
Zory, R., Millet, G., Schena, F., Bortolan, L., Rouard, A. (2006) Fatigue induced by a cross-country skiing KO sprint. Medicine \& Science in Sports \& Exercise. 38(12), 2144-2150.

URL: http://mc.manuscriptcentral.com/rspb Email: ykwon@twu.edu 


\section{Tables with captions}

\section{List of tables}

\begin{tabular}{|l|l|}
\hline Table 1. & Isometric test (Wilcoxon Signed Ranks test) \\
\hline Table 2. & Simulated game EMG test (Wilcoxon Signed Ranks test) \\
\hline Table 3. & $\begin{array}{l}\text { Table 3. Simulated game target hitting rate, Rate of Perceived Exertion } \\
\text { and maximum ball speed test (Wilcoxon Signed Ranks test) }\end{array}$ \\
\hline
\end{tabular}

Table 1. Isometric EMG test (Wilcoxon Signed Ranks test) (mean+SD)

\begin{tabular}{|l|c|c|c|c|c|c|c|c|}
\hline \multicolumn{5}{|c|}{ Mean Power Freqency (Flexion) } & \multicolumn{3}{l|}{ Mean Power Freqency (Extension) } \\
\hline Muscle & Pre & Post & Change(\%) & P value & Pre & Post & Change(\%) & P value \\
\hline $\begin{array}{l}\text { Wrist } \\
\text { extensor }\end{array}$ & $191.4 \pm 21.0$ & $183.1 \pm 27.5$ & -4.3 & 0.426 & $195.7 \pm 28.7$ & $204.4 \pm 26.0$ & 4.4 & 0.203 \\
\hline $\begin{array}{l}\text { Biceps } \\
\text { brachii }\end{array}$ & $168.8 \pm 24.6$ & $177.0 \pm 28.6$ & 4.8 & 0.055 & $205.7 \pm 31.4$ & $204.4 \pm 27.8$ & -0.6 & 0.570 \\
\hline $\begin{array}{l}\text { Triceps } \\
\text { brachii }\end{array}$ & $197.3 \pm 22.1$ & $190.9 \pm 28.8$ & -3.2 & 0.734 & $205.3 \pm 29.2$ & $210.0 \pm 23.4$ & 2.3 & 1.000 \\
\hline $\begin{array}{l}\text { Anterior } \\
\text { deltoid }\end{array}$ & $174.5 \pm 22.7$ & $173.5 \pm 18.7$ & -0.6 & 0.734 & $175.9 \pm 26.7$ & $173.5 \pm 36.2$ & -1.3 & 1.000 \\
\hline $\begin{array}{l}\text { Posterior } \\
\text { deltoid }\end{array}$ & $167.0 \pm 24.4$ & $170.8 \pm 24.9$ & 2.3 & 0.496 & $170.3 \pm 22.2$ & $175.6 \pm 18.4$ & 3.1 & 0.250 \\
\hline $\begin{array}{l}\text { Upper } \\
\text { trapezius }\end{array}$ & $166.2 \pm 20.0$ & $167.8 \pm 17.2$ & 1.0 & 0.910 & $163.4 \pm 13.7$ & $160.4 \pm 17.4$ & -1.8 & 0.426 \\
\hline
\end{tabular}

$* \mathrm{P} \leq 0.05$

Table 2. Simulated game EMG test (Wilcoxon Signed Ranks test) (mean + SD)

\begin{tabular}{|l|c|c|c|c|}
\hline & $1^{\text {st }}$ vs $72^{\text {nd }}$ throw MPF & \multicolumn{4}{|l|}{} \\
\hline Muscle & $1^{\text {st }}$ throw $(\mathrm{Hz})$ & $72^{\text {nd }}$ throw $(\mathrm{Hz})$ & Change $(\%)$ & $\mathrm{P}$ \\
\hline Wrist extensor & $182.9 \pm 27.0$ & $182.7 \pm 25.4$ & -0.1 & 0.426 \\
\hline Biceps brachii & $159.7 \pm 20.5$ & $160.1 \pm 15.6$ & 0.3 & 0.820 \\
\hline Triceps brachii & $179.0 \pm 36.1$ & $182.6 \pm 32.0$ & 0.2 & 0.734 \\
\hline $\begin{array}{l}\text { Anterior } \\
\text { deltoid }\end{array}$ & $177.7 \pm 33.4$ & $174.6 \pm 16.8$ & -1.7 & 0.652 \\
\hline $\begin{array}{l}\text { Posterior } \\
\text { deltoid }\end{array}$ & $160.0 \pm 5.3$ & $156.2 \pm 15.9$ & -2.3 & 0.570 \\
\hline $\begin{array}{l}\text { Upper } \\
\text { trapezius }\end{array}$ & $161.9 \pm 10.6$ & $149.5 \pm 15.5$ & -7.7 & $0.027^{*}$ \\
\hline
\end{tabular}

$* \mathrm{P} \leq 0.05$ 
Table 3. Simulated game target hitting rate, Rate of Perceived Exertion and maximum ball speed test (Wilcoxon Signed Ranks test) (mean+SD)

\begin{tabular}{|c|c|c|c|c|}
\hline & First 24 throws (\%) & Last 24 throws (\%) & Change (\%) & P \\
\hline \hline Hitting rate & $36.6 \pm 20.2$ & $27.3 \pm 16.0$ & -25 & $0.004^{*}$ \\
\hline & Pre & Post & Change (\%) & P \\
\hline RPE & $6.6 \pm 1.1$ & $14.4 \pm 1.9$ & 118 & $0.004 *$ \\
\hline Ball speed(m/s) & $37.9 \pm 5.6$ & $33.2 \pm 7.2$ & -12 & $0.004 *$ \\
\hline
\end{tabular}

$* \mathrm{P} \leq 0.05$ 


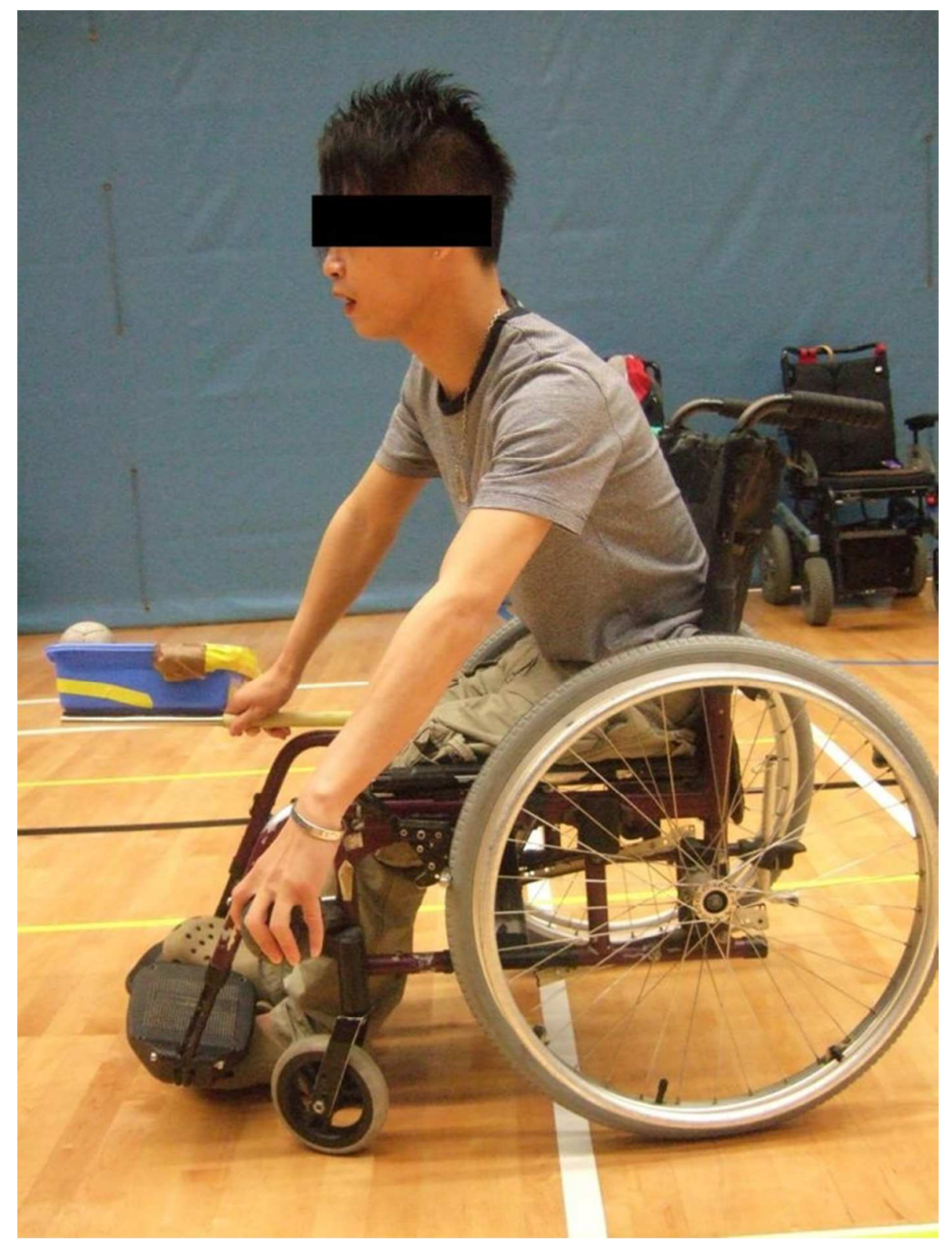

Boccia 'Under arm' throwing method with arm swimming back and forth $124 \times 165 \mathrm{~mm}(150 \times 150 \mathrm{DPI})$ 


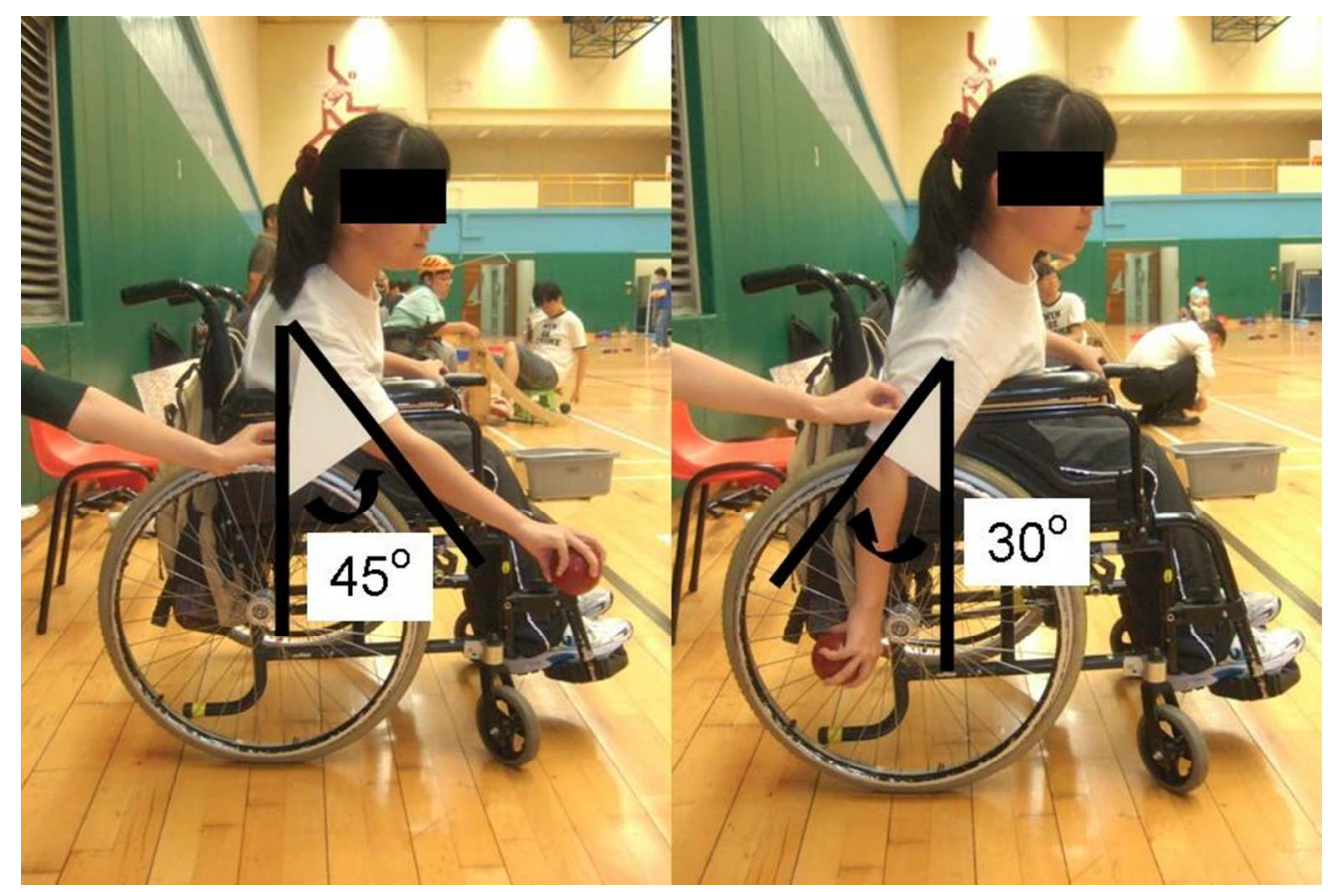

Posture for isometric flexion test in shoulder flexion at $45^{\circ}$ and for isometric extension test in shoulder extension at $30^{\circ}$ $150 \times 100 \mathrm{~mm}(150 \times 150 \mathrm{DPI})$ 
Wrist Extensor

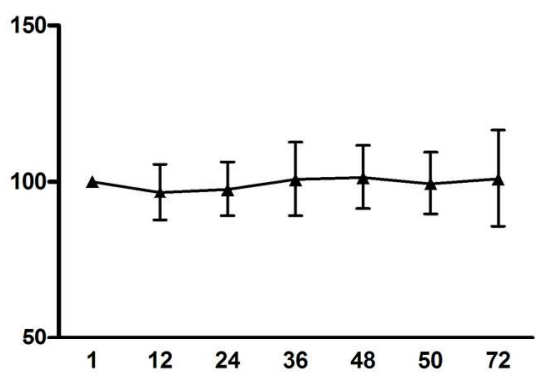

Triceps Brachii

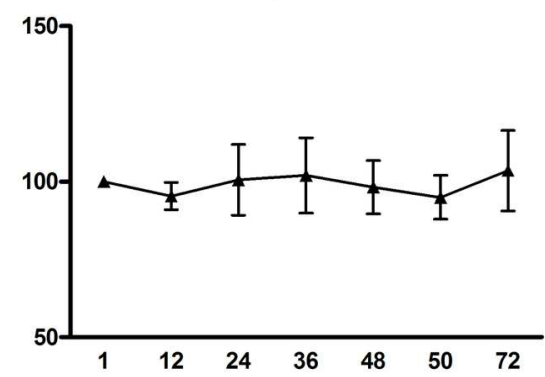

Posterior Deltoid

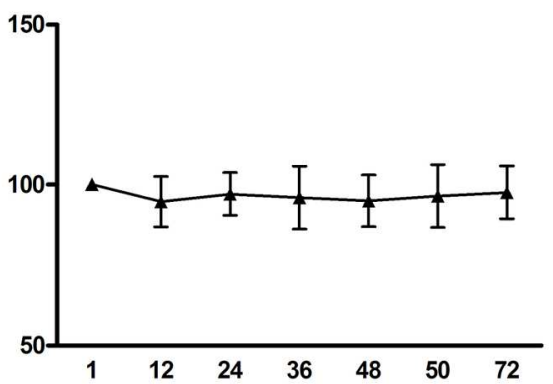

Biceps Brachii

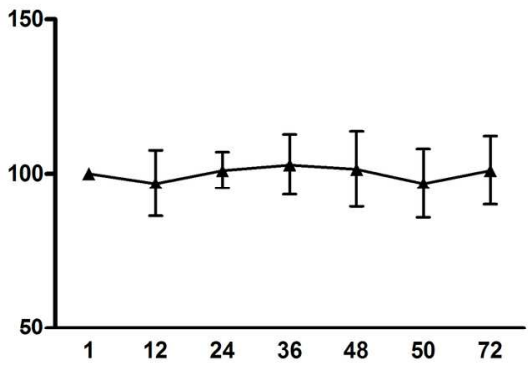

Anterior Deltoid

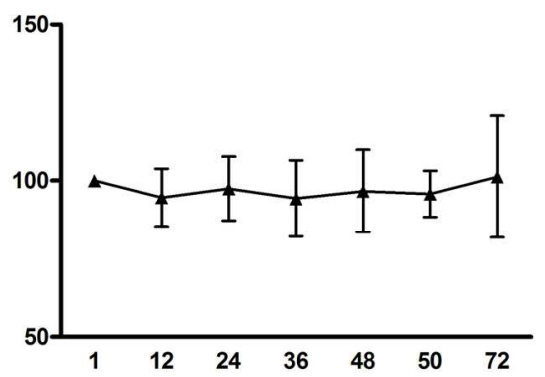

Upper Trapezius

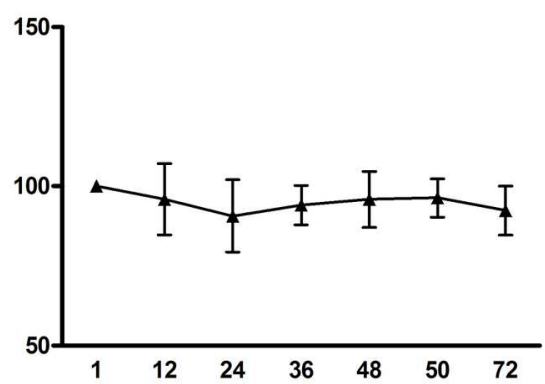

Mean power frequency (MPF) of six upper limb muscles during 72 throws $166 \times 206 \mathrm{~mm}(300 \times 300$ DPI $)$ 
In addition, please address the following:

- $\quad$ Line 304: Remove this heading.

- $\quad$ The heading was removed

- References: Remove the bullets. Check the format for the following: lines 311-312, 320-324 (edition number in the author field), 349 (page number), ... Format has been revised

- Tables: Present the data in M +- SD format. Remove \# symbol. MPF must be explaine within the table. Use the 'landscape' orientation if necessary. Tables 3 and 4 could be combined.

- $\quad$ Tables have been revised and combined

When you revise your manuscript please highlight the changes you make in the manuscript by using coloured text. 
To submit the revision, log into http://mc.manuscriptcentral.com/rspb and enter your Author Centre, where you will find your manuscript title listed under "Manuscripts with Decisions." Under "Actions," click on "Create a Revision." Your manuscript number has been appended to denote a revision.

IMPORTANT: There is a space for the author responses but ignore it. Instead, submit your responses to the comments made by the editor(s)/reviewer(s) as a main document and place it before the revised manuscript. Document any changes you made to the original manuscript as specific as possible in your response.

IMPORTANT: Your original files are available to you when you upload your revised manuscript. Please delete any redundant files before completing the submission. 
Because we are trying to facilitate timely publication of manuscripts submitted to Sports Biomechanics, your revised manuscript should be uploaded as soon as possible. If it is not possible for you to submit your revision in a reasonable amount of time, we may have to consider your paper as a new submission.

Once again, thank you for submitting your manuscript to Sports Biomechanics and I look forward to receiving your revision.

Sincerely,

Young-Hoo Kwon, Ph.D.

Editor in Chief, Sports Biomechanics

kwon3d@kwon3d.com

Associate Editor's Comments to Author: 
Associate Editor: Fleisig, Glenn

Comments to Author:

The authors have done a nice job revising the paper. Please address these additional corrections -

Line 42 Delete the sentence: “Hong Kong Boccia athletes... in the past few years."

$\underline{\text { Sentence has been deleted. }}$

Line 43 Reword this sentence. It doesn't make sense right now: “This fast growing indoor sport... worldwide."

This sentence has been reworded.

Line 47 This sentence implies that "the presence and extent" are the people who understand muscle recruitment. Please fix the English. 
This sentence has been revised.

Line 54 "... supplied through blood circulation"

This sentence has been revised.

Line 68 “De Luca recommended using the MPF calculated from the frequency

spectrum of the EMG signal as the fatigue index because..."

This sentence has been revised.

Line 140 "A five minute rest..."

This sentence has been revised.

Line 166 "the data were filtered..."

This sentence has been revised. 
Line 185 "There was no significant difference of MPF in any tested muscle..."

This sentence has been revised.

Line 194 "There were decreasing MPF trends..."

This sentence has been revised.

Line 195 "but were deemed..."

This sentence has been revised.

Line 199 "shown in any tested upper limb muscle."

This sentence has been revised.

Line 225 Uses commas instead of semicolons in this sentence.

This sentence has been revised. 
Line 232 The phrase "most common muscle" is not clear. I think you should change the wording.

This sentence has been revised.

Line 249 "for any tested upper limb muscle"

This sentence has been revised.

Line 267 “may be due not only to muscle fatigue, but also factors outside the neuromuscular system."

This sentence has been revised.

Line 290 “However, all the available qualified Boccia athletes were recruited in this study."

This sentence has been revised. 
Line 304 Delete "7. Future Studies". This can just be the second paragraph in conclusions.

The title has been deleted.

Tables and Figures Table 1 and Figures $3 \& 4$ are redundant. Remove one or the other. If you keep the figures and eliminate the table, then simply place a «*" above the pairs of bars with significant differences.

Figures $3 \& 4$ were removed.

Figures

Reviewer(s)' Comments to Author:

Reviewer: 1

Comments to the Author 
The changes are ok

Reviewer: 2

Comments to the Author

Dear authors,

The manuscript truly improved since the last time; however I still have some minor remarks.

INTRODUCTION

P13L63-65 .This strong statement (»The decrease of $\mathrm{pH} . . . \ll)$ needs to be supported with some references.

$\underline{\text { Reference has been added. }}$

P13L69 De Luca (year)...

This sentence has been revised. 
P14 L 74-80 List a few studies where the MNF decrease was used to evaluate fatigue in different sports or movements (e.g. cycling, swimming, etc).

I listed them in discussion part.

\section{METHODS}

P15L118 »..placed in the middle...« Comment: SENIAM recommendations should be used when dealing with EMG.

$\underline{\text { Reference has been added. }}$

$P 17 L 157$ »EMG data were compared to obtain a MPF.« Sentence is not clear.

This sentence has been revised.

\section{RESULTS}

P18L187-189 -Show $p$ value. A «trend « means that $p$ values were close to 0.05 . Were they?

P19L195 - same remark as above. 
Those phrases have been rephrased.

DISCUSSION

P20L236 -242. You have chosen not to analyse EMG amplitude, therefore you can not discuss it.

This is a misleading word. This paragraph has been revised.

However you should discuss the MPF decrease, like you do from L243-247 add some more references.

All these are references that I can find about the relationship of change of EMG and performance.

P21L267-272: Comment: In my opinion the increased RPE and the decreased maximal ball velocity and hitting rate, clearly showed the presence of fatigue; however the methods you've used (the decrease of MPF) didn`t detect it. Perhaps you should lead the discussion this way .In my first review I already expressed my opinion that isometric tests performed were not suitable. 
I think I should say not all the muscles that I measured showed decrease of

MPF. I want to elaborate a bit more about subjective RPE score in this

paragraph. I have also discussed about the isometric test in L255.

L272 - change "was" to were

This sentence has been revised. 